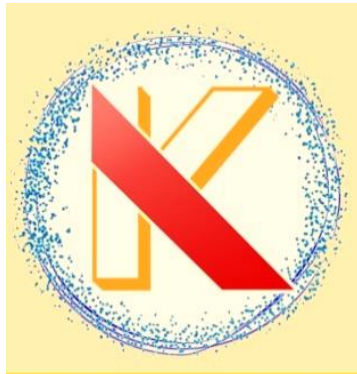

\title{
Konversi Karat Besi Menjadi Besi (III) Sulfat dan Pemanfaatannya Sebagai Adsorpsi Pewarna Tekstil
}

\section{[Iron Rust to Iron (III) Sulphate Conversion and the Utilization as Textile Dye Adsoption]}

\author{
Agustinus Ngatin, Fatimah, Widya Fitria Nur Fauziah, Rony Pasonang Sihombing* \\ Department of Chemical Engineering, Politeknik Negeri Bandung \\ *Corresponding author: rony.pasonang.sihombing@polban.ac.id
}

\begin{abstract}
Iron rust was an iron oxide compound that was less attractive, dirty, brown in color, and could pollute the environment, causing water to turn brown. To minimize iron contamination, conversion was carried out into iron (III) sulfate which was useful as an adsorbent for textile dyes. The purpose of this study was to determine the effect of sulfuric acid concentration and volume of $\mathrm{H}_{2} \mathrm{O}_{2} 10 \%$ used to convert iron rust into optimal iron (III) sulfate compounds. The method used was a laboratory experiment on a batch scale and the hydrate content in iron (III) sulfate was carried out by the gravimetric method and its ability as an adsorbent was carried out based on the adsorption of dyes using the spectrophotometric method. The results showed that a reactor filled with $3 \mathrm{grams}$ of iron rust powder and $100 \mathrm{~mL}$ of sulfuric acid was stirred at $425 \mathrm{rpm}$ at $80{ }^{\circ} \mathrm{C}$ for 30 minutes, added $15 \mathrm{ml} 10 \%$ $\mathrm{H}_{2} \mathrm{O}_{2}$ followed by stirring and heating until the solution was saturated, cooled to form crystals. The crystalline yield in these conditions was the increase in sulfuric acid concentration which resulted in low process efficiency, namely $30.34 \%$ at $50 \%$ sulfuric acid concentration and $15 \mathrm{~mL} 10 \% \mathrm{H}_{2} \mathrm{O}_{2}$. The addition of $10 \% \mathrm{H}_{2} \mathrm{O}_{2}$ solution to $50 \mathrm{~mL}$ of $20 \%$ sulfuric acid solution and 3.0 grams of a carat as much as $5 \mathrm{~mL}-10 \mathrm{~mL} 10 \% \mathrm{H}_{2} \mathrm{O}_{2}$ produced iron (III) sulfate with $26.53 \%$ process efficiency. Iron (III) sulfate is a white, light gray crystal with the chemical formula $\mathrm{Fe}_{2}\left(\mathrm{SO}_{4}\right)_{3.5}$ $\mathrm{H}_{2} \mathrm{O}$ which was a rhombic shaped crystal. and able to absorb the dye which showed that $1.0 \mathrm{~g}$ of iron (III) sulfate was able to absorb the highest amount of red dye in a volume of $100 \mathrm{~mL}$ of textile dye solution.
\end{abstract}

Keywords: Iron rust, synthesis, iron (III), sulfuric acid, textile dyes

\begin{abstract}
ABSTRAK. Karat besi merupakan senyawa besi oksida yang kurang menarik, kotor, berwarna coklat dan dapat mencemari lingkungan, serta menyebabkan air berwarna coklat. Untuk meminimalis pencemaran besi dilakukan pengubahan menjadi senyawa besi (III) sulfat yang bermanfaat sebagai pengadsorpsi zat warna.tekstil. Tujuan penelitian ini adalah menentukan pengaruh konsentrasi asam sulfat dan volume $\mathrm{H}_{2} \mathrm{O}_{2} 10 \%$ yang digunakan untuk mengubah karat besi menjadi senyawa besi (III) sulfat yang optimal. Metode yang digunakan adalah eksperimen di laboratorium dalam skala batch dan kandungan hidrat dalam besi (III) sulfat dilakukan dengan metode gravimetri serta kemampuannya sebagai adsorben dilakukan berdasarkan adsorbansi pewarna dengan metode spektrofotometri. Hasilnya menunjukkan bahwa suatu reaktor dengan 3 gram serbuk karat besi dan $100 \mathrm{~mL}$ asam sulfat dilakukan pengadukan $425 \mathrm{rpm}$ pada suhu $80{ }^{\circ} \mathrm{C}$ selama 30 menit, ditambahkan $15 \mathrm{ml} \mathrm{H}_{2} \mathrm{O}_{2} \quad 10 \%$ dilanjutkan pengadukan dan pemanasan sampai larutan jenuh, didinginkan sampai membentuk kristal. Hasil kristal pada kondisi tersebut adalah pada peningkatan konsentrasi asam sulfat menghasilkan efisiensi proses yang masih rendah yaitu $30,34 \%$ pada konsentrasi asam sulfat $50 \%$ dan $15 \mathrm{~mL} \mathrm{H}_{2} \mathrm{O}_{2} 10 \%$. Penambahan larutan $\mathrm{H}_{2} \mathrm{O}_{2} 10 \%$ ke dalam $50 \mathrm{~mL}$ larutan asam sufat $20 \%$ dan 3,0 gram karat sebanyak $5 \mathrm{~mL}-10 \mathrm{~mL} \mathrm{H}_{2} \mathrm{O}_{2} \quad 10 \%$ menghasilkan besi (III) sulfat dengan efisiesn proses $26,53 \%$. Besi (III) sulfat merupakan kristal berwarna putih abu-abu terang,dengan rumus kimia $\mathrm{Fe}_{2}\left(\mathrm{SO}_{4}\right)_{3} .5 \mathrm{H}_{2} \mathrm{O}$ yang merupakan kristal berbentuk rombis. dan mampu menyerap pewarna yang ditunjukkan bahwa $1,0 \mathrm{~g}$ besi (III) sulfat mampu menyerap pewarna merah dengan jumlah terbanyak dalam volume $100 \mathrm{~mL}$ larutan pewarna tekstil.
\end{abstract}

Kata kunci: Karat besi, sintesis, besi (III), asam sulfat, pewarna tekstil 
Riwayat artikel: Diterima 17 Oktober 2020, Disetujui 26 November 2020

Cara sitasi: Ngatin, A., Fatimah., Fauziah WFN., \& Sihombing, RP. (2020). Konversi Karat Besi Menjadi Besi (III) Sulfat dan Pemanfaatannya Sebagai Adsorpsi Pewarna Tekstil. KOVALEN: Jurnal Riset Kimia, 6(3): 177-183.

DOI: https://doi.org/10.22487/kovalen.2020.v6.i3.15308

\section{LATAR BELAKANG}

Besi (III) sulfat $\left[\mathrm{Fe}_{2}\left(\mathrm{SO}_{4}\right)_{3}\right]$ merupakan kristal berwarna putih abu-abu bersifat hidratt dan meleleh pada suhu $175^{\circ} \mathrm{C}$. Besi (III) sulfat merupakan hasil oksidasi dari besi (II) sulfat mempunyai daya koagulasi yang lebih besar (Vogel, 1985), mempunyai efek koagulan 11x lebih besar dibandingkan besi (II) (Undang. Republik Indonesia Nomor 82 Tahun 2001). Untuk itu besi (II) sulfat diubah menjadi besi (III) sulfat agar dapat meningkatkan manfaat dari limbah besi. Besi (III) sulfat dapat digunakan sebagai bahan koagulan pada penjernihan air dan penghilangan zat warna pada limbah tekstil. Limbah zat warna dapat diatasi dengan metode kimia dan fisika seperti adsorpsi, penukaran ion, koagulasi-flokulasi, oksidasi dan metode elektrokimia (Ennil, 2017; Köse \& Çalişkan, 2016). Penghilangan zat warna limbah tekstil ini dapat dilakukan menggunakan besi (III) sulfat dengan pengadukan 60 - 100 rpm selama 1 - 3 menit hingga pada rentang pH 5 (Risdianto, 2007).

Besi (III) sulfat dapat dihasilkan dari reaksi oksidasi besi(II) sulfat, yang dihasilkan dari reaksi besi dengan asam sulfat encer sesuai reaksi:

$$
\mathrm{Fe}(\mathrm{s})+\mathrm{H}_{2} \mathrm{SO}_{4}(\mathrm{aq}) \rightarrow \mathrm{FeSO}_{4}(\mathrm{aq})+\mathrm{H}_{2}(\mathrm{~g}) \ldots
$$

Reaksi ini terjadi akibat besi berkarat masih mengandung besi. Besi (II) sulfat $\left[\mathrm{FeSO}_{4}\right]$ direaksikan dengan hidrogen peroksida $\left(\mathrm{H}_{2} \mathrm{O}_{2}\right)$ menjadi besi (III) sulfat, sesuai reaksi ;

$2 \mathrm{FeSO}_{4}+\mathrm{H}_{2} \mathrm{SO}_{4}+\mathrm{H}_{2} \mathrm{O}_{2} \rightarrow \mathrm{Fe}_{2}\left(\mathrm{SO}_{4}\right)_{3}+2 \mathrm{H}_{2} \mathrm{O} \ldots$ (2)

Hidrogen peroksida $\left(\mathrm{H}_{2} \mathrm{O}_{2}\right)$ merupakan oksidator yang mengoksidasi besi (II) menjadi besi (III). Produk besi (III) sulfat dapat dimanfaatkan sebagai adsorpsi pewarna. sehingga penelitian ini memiliki nilai tinggi yang dapat mengembangkan ilmu serta mengurangi limbah atau pencemaran lingkungan. Karat besi merupakan hasil oksida besi dengan udara yang mengandung uap air membentuk senyawa oksida sesuai reaksi.

$$
\mathrm{Fe}(\mathrm{s})+1 / 2 \mathrm{O}_{2}+\mathrm{H}_{2} \mathrm{O}(\mathrm{l}) \rightarrow \mathrm{Fe}(\mathrm{OH})_{2}
$$

Besi (II) hidroksida $\left[\mathrm{Fe}(\mathrm{OH})_{2}\right]$ mengalami oksidasi secara alami oleh air dan udara menjadi besi (III) hidroksida $\left[\mathrm{Fe}(\mathrm{OH})_{3}\right]$, sesuai reaksi:

$\mathrm{Fe}(\mathrm{OH})_{2}(\mathrm{~s})+\mathrm{O}_{2}(\mathrm{~g})+2 \mathrm{H}_{2} \mathrm{O}(\mathrm{l}) \rightarrow 4 \mathrm{Fe}(\mathrm{OH})_{3}(\mathrm{~s}) \ldots(4)$

Besi (III) hidroksida berubah menjadi senyawa besi (III) oksida $\left(\mathrm{Fe}_{2} \mathrm{O}_{3}\right)$ atau karat yang berwarna merah kecoklatan (Megawati, 2004; Rönnholm et al., 1999), yang reaksinya:

$$
4 \mathrm{Fe}(\mathrm{OH})_{3}(\mathrm{~s}) \rightarrow 2 \mathrm{Fe}_{2} \mathrm{O}_{3}(\mathrm{~s})+6 \mathrm{H}_{2} \mathrm{O}(\mathrm{l})
$$

Karat besi merupakan senyawa besi (III) oksida yang sering disebut "karat". Karat adalah produk reaksi logam besi dengan udara lembab yang mempunyai rumus kimia $\mathrm{Fe}_{2} \mathrm{O}_{3}$ . $\mathrm{xH}_{2} \mathrm{O}$ (Aladin et al., 2010; Walker, 1993). Penelitian sebelumnya menggunakan besi klorida untuk digunakan sebagai solusi limbah warna (Zahrim et al., 2011). Namun dalam penelitian ini, sintesis yang digunakan adalah sintesis besi (III) sulfat.

Karat besi yang terbentuk berwarna coklat kehitaman merupakan limbah logam yang dapat mencemari lingkungan. Untuk mengurangi limbah besi, dilakukan upaya untuk mengubah menjadi senyawa yang bermanfaat yaitu dengan mensintesisnya 
menjadi besi (III) sulfat atau senyawa besi yang lain. Ada beberapa referensi yang dapat dilakukan sebagai tujuan akhir dari sintesis ini. Senyawa besi antara lain adalah besi (II) sulfat sebagai bahan pengikat zat warna dan sumber ion $\mathrm{Fe}^{2+}$ untuk keperluan analisis volumetrik, besi (III) sulfat atau besi (III) ammonium sulfat sebagai bahan koagulan pengolahan limbah industri dan air jernih serta pengikat zat warna, dan besi (III) klorida sebagai pelarut lapisan tembaga di permukaan PCB (Pass et al., 1974; Vogel, 1985).

Besi yang sudah mengalami proses korosi atau berkarat merupakan material logam yang sudah tidak dimanfaatkan, karena kotor dan umumnya dibuang sebagai limbah atau barang bekas yang dijual dengan harga yang murah berkisar Rp4000/kg. Namun, jika besi yang sudah berubah menjadi karat diolah menjadi senyawa besi (III) sulfat yang dapat digunakan untuk bahan koagulan dengan harga sekitar Rp15.000 /kg, akan dapat meningkatkan nilai ekonomi dan mengurangi pencemaran lingkungan. Penelitian lain menyimpulkan bahwa limbah besi dapat digunakan untuk industri kreatif (Indrasari, 2020).

Berdasarkan uraian tersebut, maka permasalahan yang timbul adalah bagaimana konsentarsi $\mathrm{H}_{2} \mathrm{SO}_{4}$ dan volume $\mathrm{H}_{2} \mathrm{O}_{2} \quad 10 \%$ diperlukan untuk setiap 3,0 gram serbuk besi yang sudah mengalami pengkaratan untuk menghasilkan persen yield besi(III) sulfat yang maksimal, dan bagaimana karakteristik kristal besi (III) sulfat yang dihasilkan? Untuk itu, yang menjadi tujuan penelitian adalah menentukan pengaruh konsentrasi larutan asam sulfat $\left(\mathrm{H}_{2} \mathrm{SO}_{4}\right)$ yang diperlukan untuk 3,0 gram serbuk karat besi, menentukan volume $\mathrm{H}_{2} \mathrm{O}_{2} \quad 10 \%$ untuk menghasilkan persen yield maksimum, dan menentukan karakteristik besi (III) sulfat yang dihasilkan.

\section{METODOLOGI PENELITIAN}

\section{Bahan dan Peralatan}

Bahan kimia yang diperlukan meliputi karat besi, larutan asam sulfat pekat, hidrogen peroksida $10 \%$. Instrumen pada sintesis senyawa besi (III) sulfat menggunakan neraca analitik, alat gelas seperti gelas kimia, gelas ukur, pemanas yang dilengkapi dengan pengaduk magnit.

\section{Prosedur Penelitian}

Proses sintesis besi (III) sulfat dilakukan dengan mereaksikan karat dengan larutan asam sulfat bervariasi konsentrasi pada suhu $80^{\circ} \mathrm{C}$ diaduk selama 45 menit, ditambah $15 \mathrm{~mL}$ larutan hidrogen peroksida $10 \%$ sampai terbentuk larutan jernih, dipanaskan, didinginkan sampai terbentuk kristal putih jernih. Kristal dikeringkan, ditimbang, diamati dan dicatat. Untuk sintesis besi (III) sulfat secara skematis dapat disajikan dalam bentuk diagram seperti pada Gambar 1.

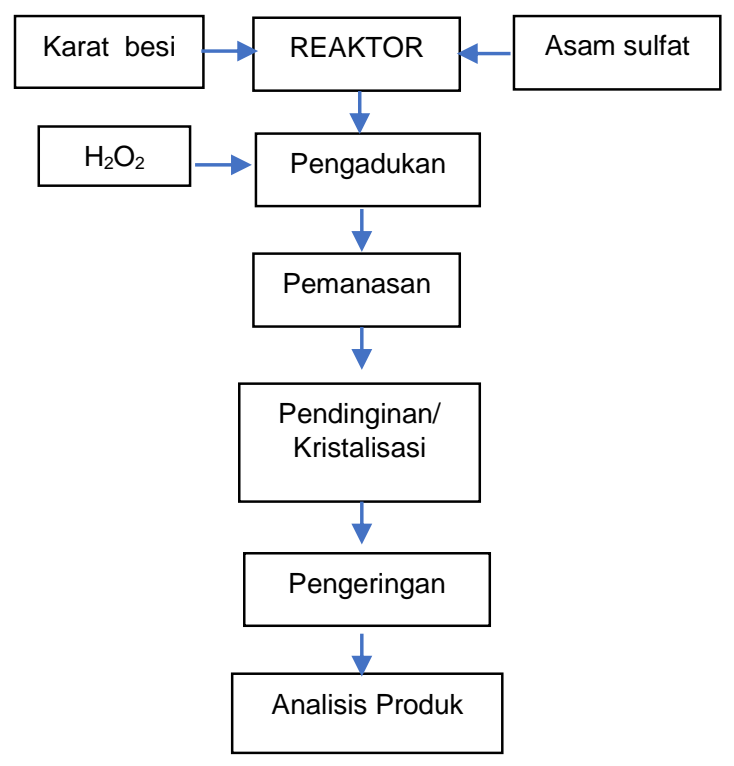

Gambar 1. Sintesis besi (III) sulfat 


\section{HASIL DAN PEMBAHASAN}

Sintesis besi (III) sulfat menggunakan bahan baku karat besi berbentuk serbuk yang berwarna coklat, direaksikan dengan larutan asam sulfat $20 \%$ menghasilkan larutan yang berwarna hijau dan coklat. Dengan penambahan larutan hidrogen peroksida $\left(\mathrm{H}_{2} \mathrm{O}_{2}\right)$, larutan tersebut berubah menjadi
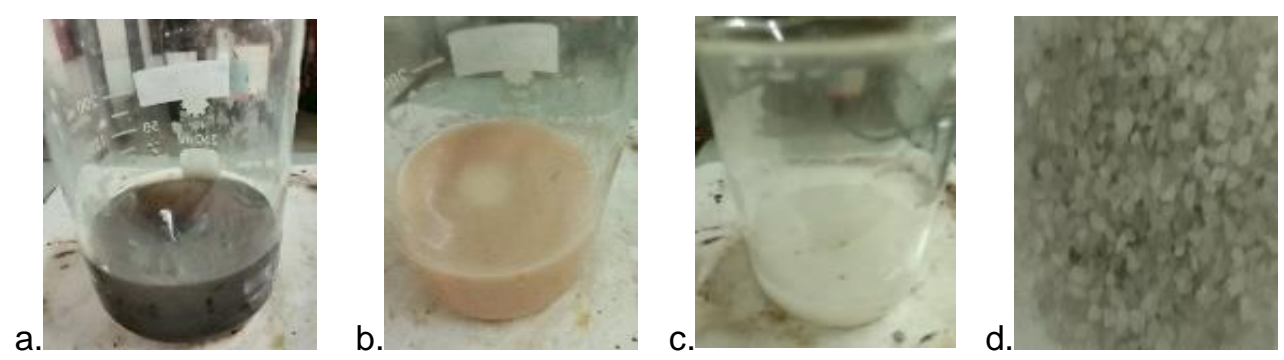

Gambar 2. a) penambahan $\mathrm{H}_{2} \mathrm{SO}_{4}$, b) awal $+\mathrm{H}_{2} \mathrm{O}_{2}$, c) larutan jenuh, d) Kristal

Berdasarkan Gambar 2a, warna hijau coklat akibat terjadi reaksi besi berkarat ( $\mathrm{FeO}$ dan $\left.\mathrm{Fe}_{2} \mathrm{O}_{3}\right)$ dengan asam sulfat akan menghasilkan senyawa besi (II) sulfat dan besi (III) sulfat seperti ditunjukkan pada Reaksi 1. Pada Gambar 2b, larutan berubah menjadi coklat muda saat penambahan hidrogen peroksida akibat terjadi reaksi oksidasi yang akhirnya berubah menjadi keruh saat semua ion $\mathrm{Fe}^{2+}$ berubah menjadi $\mathrm{Fe}^{3+}$ seperti ditunjukkan pada Reaksi 2.

\section{Pengaruh Konsentrasi Asam Sulfat}

Konsentrasi asam sulfat adalah $10 \%$, $20 \%$, dan $50 \%$ dengan volume $100 \mathrm{~mL}$. Setelah itu, terdapat penambahan $15 \mathrm{~mL}$ hidrogen peroksida $\left(\mathrm{H}_{2} \mathrm{O}_{2}\right) \quad 10 \%$ dan menghasilkan massa produk.

Gambar 3 menunjukkan bahwa konsentrasi larutan asam sulfat sedikit mempengaruhi produk yaitu semakin meningkatnya konsentrasi asam sulfat dari $10 \%$ hingga $50 \%$, massa produk yang dihasilkan mengalami sedikit kenaikan yaitu $2,924 \mathrm{~g}$ untuk $10 \%$ sampai $3,254 \mathrm{~g}$ untuk asam larutan yang berwarna coklat dimana seiring waktu akan menghasilkan endapan berupa kristal berwarna putih abu-abu terang dengan $\mathrm{pH}$ larutan mencapai 1-2. Secara visual hasil sintesis besi (III) sulfat dapat ditunjukkan pada Gambar 2. sulfat $50 \%$. Hal ini menunjukkan bahwa pengaruh konsentrasi asam sulfat tidak signifikan. Hal ini kemungkinan disebabkan karena konsentrasi asam sulfat $10 \%$ hingga $50 \%$ mempunyai sifat sebagai pereaksi atau pelarut karat besi dan bersifat korosif (Walker, 1993).

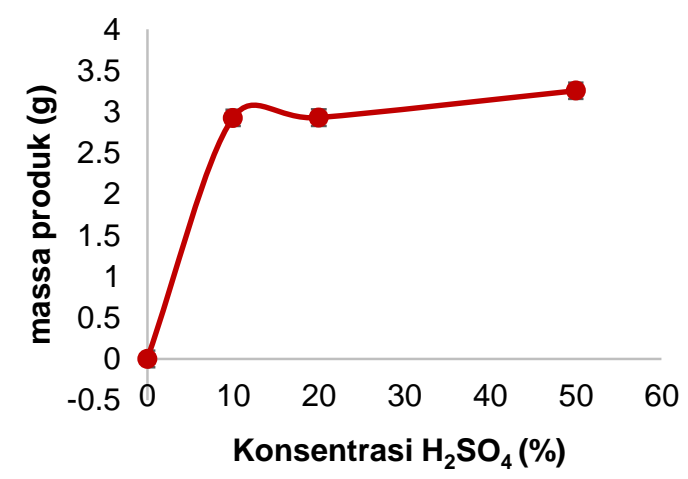

Gambar 3. Pengaruh konsentrasi asam sulfat terhadap massa produk

Pengaruh konsentrasi asam sulfat terhadap \% produk atau efisiensi proses seperti ditunjukkan pada Gambar 4. Konsentrasi larutan asam sulfat $10 \%$ sampai $50 \%$ belum menunjukkan pengaruhnya pada penambahan asam sulfat dengan konsentrasi $20 \%$ sampai $50 \%$ dengan volume $100 \mathrm{~mL}$ yang ditambahkan 
ke dalam 3,0 gram serbuk karat besi (Gambar 4). Penambahan ini menghasilkan \% produk yang masih rendah yaitu $27,25 \%$ hingga $30,34 \%$. Hal ini kemungkinan disebabkan karena jumlah volumenya terlalu besar, sehingga jumlah karat besi yang larut meningkat dan endapan besi (III) sulfat ikut larut di dalamnya. Perbandingan mol serbuk karat besi dengan asam sulfat cukup jauh yaitu mulai 1:3 sampai 1:18. Hal tersebut yang menyebabkan \% produknya masih relatif rendah yaitu masih di bawah 35\%.

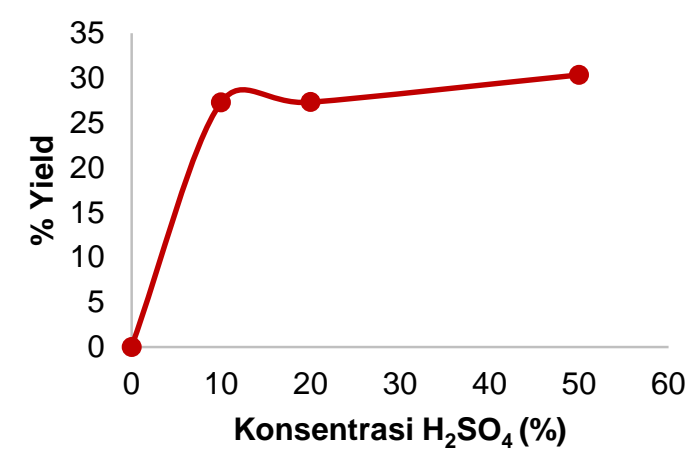

Gambar 4. Pengaruh konsentrasi asam sulfat terhadap $\%$ yield

Untuk melihat hal tersebut, variasi volume asam sulfat dengan konsentrasi $20 \%$ yaitu $30 \mathrm{~mL}, 50 \mathrm{~mL}$ dan $70 \mathrm{~mL}$ dengan penambahan $15 \mathrm{~mL}$ hidrogen peroksida $\left(\mathrm{H}_{2} \mathrm{O}_{2}\right) \quad 10 \%$ dihasilkan hubungan volume terhadap \%produk sebagaimana ditunjukkan pada Gambar 5.

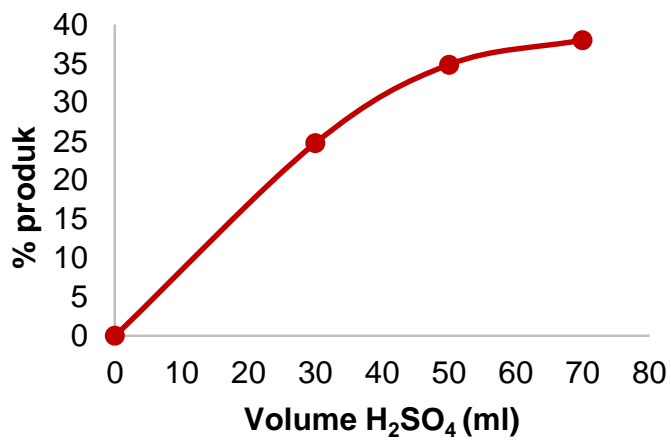

Gambar 5. Pengaruh volume $\mathrm{H}_{2} \mathrm{SO}_{4}$ terhadap \%produk
Gambar 5 menjelaskan pengaruh volume larutan asam sulfat terhadap \% produk yaitu dengan meningkatnya volume $\mathrm{H}_{2} \mathrm{SO}_{4}, \%$ produk yang dihasilkan juga akan meningkat. Dimulai dengan penambahan $30 \mathrm{~mL}$ asam sulfat 20\% (nilai \%produk adalah 24,73), hingga penambahan $70 \mathrm{~mL}$ asam sulfat $20 \%$ yang menghasilkan \% produk 37,95. Jika dibandingkan dengan pengaruh konsentrasi dimana volume yang lebih kecil digunakan, \% produk yang dihasilkan relatif lebih tinggi meskipun masih di bawah 50\%. Hal ini disebabkan perbandingan mol serbuk karat besi dengan asam sulfat hampir berdekatan yaitu 1:3,5.

\section{Pengaruh Volume $\mathrm{H}_{2} \mathrm{O}_{2}$}

Hidrogen peroksida $\left(\mathrm{H}_{2} \mathrm{O}_{2}\right)$ berfungsi untuk mengoksidasi ion $\mathrm{Fe}^{2+}$ menjadi $\mathrm{Fe}^{3+}$, sehingga dengan semakin meningkatnya jumlah hidrogen peroksida berarti semakin meningkat pula jumlah ion $\mathrm{Fe}^{3+}$ dan diharapkan menghasilkan senyawa besi (III) sulfat yang semakin meningkat. Persen produk dengan variasi volume hidrogen peroksida ditunjukkan pada Gambar 6

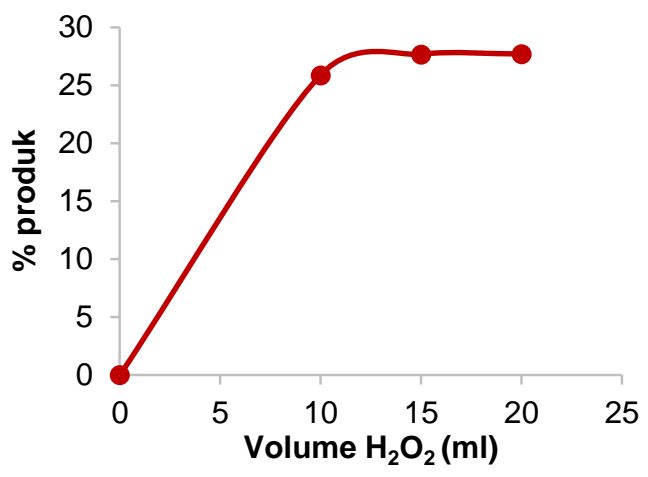

Gambar 6. Pengaruh $\mathrm{H}_{2} \mathrm{O}_{2}$ terhadap \%produk

Gambar 6 menunjukkan bahwa penambahan $10 \mathrm{ml}, 15 \mathrm{~mL}$, dan $20 \mathrm{~mL}$ hidrogen peroksida menghasilkan \% produk yang hampir sama. Dimana hasilnya adalah 25,87\%, $27,67 \%$, dan $27,68 \%$. Ini berarti dengan 
penambahan $10 \mathrm{~mL} \mathrm{H} \mathrm{H}_{2}$ 10\% sudah mampu mengoksidasi $\mathrm{Fe}^{2+}$ menjadi ${ }^{3+}$, sehingga dapat disimpulkan bahwa sintesis senyawa besi (III) sulfat dengan penambahan $15 \mathrm{~mL}$ dan $20 \mathrm{~mL}$ $\mathrm{H}_{2} \mathrm{O}_{2} \quad 10 \%$ tidak menunjukkan peningkatan yang signifikan. Untuk itu, dengan bahan karat besi yang sama, penelitian dilakukan dengan penambahan $\mathrm{H}_{2} \mathrm{O}_{2} 10 \%$ sebanyak $5 \mathrm{~mL}, 7,5$ $\mathrm{mL}$, dan $10 \mathrm{~mL}$ ke dalam 3,0 gram besi berkarat dan $50 \mathrm{~mL}$ asam sulfat $20 \%$.

Persen produk yang dihasilkan antara lain mencapai $26,53 \%$, untuk penambahan $5 \mathrm{~mL}$, $26,29 \%$ untuk $7,5 \mathrm{~mL}$ dan $26,31 \%$ untuk $10 \mathrm{~mL}$ sehingga pada penambahan sebanyak $5,0 \mathrm{~mL}$ larutan $\mathrm{H}_{2} \mathrm{O}_{2}$ didapatkan kondisi maksimum yang mencapai $26,53 \%$ (Gambar 7 ). Sehingga dapat disimpulkan bahwa volume hidrogen peroksida yang diperlukan untuk mengoksidasi $\mathrm{Fe}{ }^{2+}$ menjadi $\mathrm{Fe}^{3+}$ cukup $5 \mathrm{~mL}$ untuk menghasilkan produk sebesar $26,53 \%$ dengan rendemen $94 \%$.

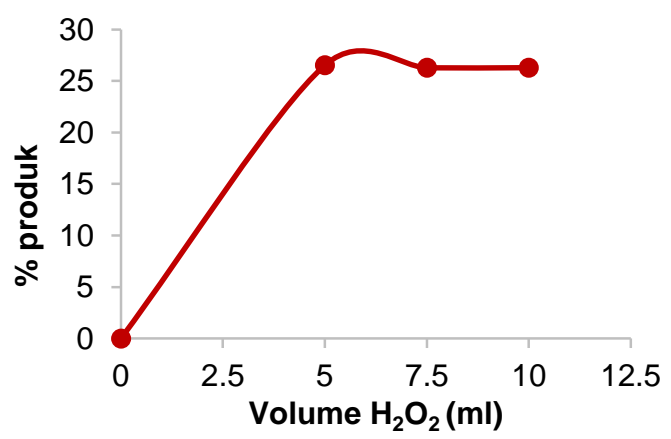

Gambar 7. Pengaruh $\mathrm{H}_{2} \mathrm{O}_{2}$ terhadap \%produk

\section{Karakteristik Senyawa Besi (III) Sulfat}

Karakteristik besi (III) sulfat yang dihasilkan berwarna putih abu-abu terang, dengan titik leleh $175^{\circ} \mathrm{C}$ dan mengikat 5 molekul air $\left(\mathrm{H}_{2} \mathrm{O}\right)$. Sehingga mempunyai rumus kimia $\mathrm{Fe}_{2}\left(\mathrm{SO}_{4}\right)_{3} .5 \mathrm{H}_{2} \mathrm{O}$ dengan nama besi (III) sulfat penta hidrat. Senyawa ini mempunyai bentuk kristal struktur rombis (Pass et al., 1974; Vogel, 1985) serta dapat mengadsorpsi pewarna merah dengan jumlah penambahan besi (III) sulfat ke dalam $100 \mathrm{~mL}$ larutan pewarna terhadap absorbance dengan menggunakan spektrofotometer.

Gambar 8 menunjukkan bahwa pada penambahan $1,0 \mathrm{~g}$ besi (III) sulfat ke dalam 100 $\mathrm{mL}$ larutan pewarna menghasilkan Absorbansi terendah. Menurut hukum Beer bahwa absorbansi berbanding lurus dengan konsentrasi pewarna (Olsen, 1986) . Sehingga penambahan $1,0 \mathrm{~g}$ besi (III) sulfat menunjukkan kondisi optimal untuk mengadsorpsi pewarana dalam volume $100 \mathrm{~mL}$ larutan setelah kontak selama 1 jam dengan pengadukan 425 rpm. Pada aplikasinya besi(III) sulfat mampu mengadsorpsi pewarna tekstil pada $\mathrm{pH} 7$ dengan penambahan $1,0 \mathrm{~g} / \mathrm{L}$ dengan efisiensi sekitar 80\% (Köse et al., 2016).

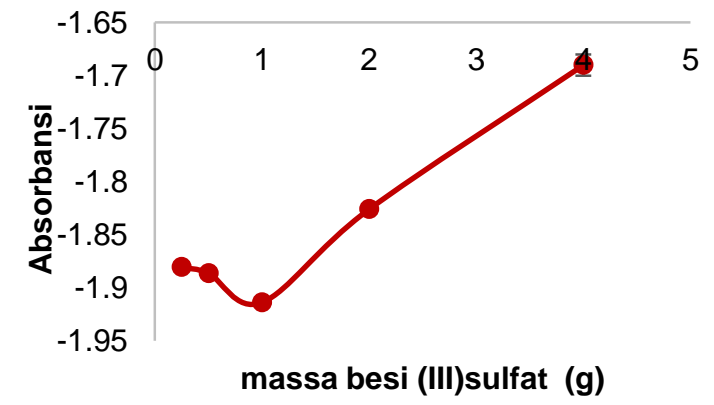

Gambar 8. Pengaruh massa besi (III) sulfat terhadap absorbansi

\section{KESIMPULAN}

Berdasarkan hasil dan pembahasan dapat disimpulkan bahwa peningkatan konsentrasi asam sulfat menghasilkan peningkatan \% produk. Penambahan $100 \mathrm{~mL}$ larutan asam sulfat $50 \%$ ke dalam 3,0gram karat besi menghasilkan \% produk dengan efisisensi mencapai $30,34 \%$. Pengaruh volume $\mathrm{H}_{2} \mathrm{O}_{2}$ $10 \%$ kurang signifikan karena pada penambahan $5 \mathrm{~mL}, 10 \mathrm{~mL}$, dan $15 \mathrm{~mL} \mathrm{H} \mathrm{H}_{2} 10 \%$ ke dalam larutan $50 \mathrm{~mL}$ asam sulfat $20 \%$ terhadap 3,0 gram karat besi menunjukkan hasil yang sampir sama yaitu $26,53 \%$ produk. 
Karakteristik besi (III) sulfat mempunyai kristal berwarna putih abu-abu terang dengan rumus kimia $\mathrm{Fe}_{2}\left(\mathrm{SO}_{4}\right)_{3} \cdot 5 \mathrm{H}_{2} \mathrm{O}$. Besi (III) Sulfat berbentuk kristal rombis dan bersifat higroskopis serta dapat digunakan untuk mengadsorpsi pewarna tekstil. Kondisi operasi maupun bahan baku dapat dijadikan pertimbangan untuk dapat menghasilkan \% produk yang lebih baik lagi.

\section{UCAPAN TERIMA KASIH}

Penelitian ini dibiayai oleh Politeknik Negeri Bandung melalui Penelitian Pemula menggunakan dana PNBP dengan Surat Perjanjian No: 140.8/PL1.R7/PG.00.03/2020.

\section{DAFTAR PUSTAKA}

Aladin, A., Syarif, T., \& Wiyani, L. (2010). Pengolahan Serbuk Limbah Besi Menjadi Besi ( III ): Tinjauan Kinetika Model Quasi Steady State. Reaktor, 13(2): 74-80.

Ennil Bektaş, T. (2017). Reduction dye in paint and construction chemicals wastewater by improved coagulation-flocculation process. Water Science and Technology, 76(10): 2816-2820.

Indrasari, L. D. (2020). Pemberdayaan Masyarakat melalui Pemanfaatan Limbah Besi dalam pembuatan Produk "CIRCLE HANGER" sebagai Peningkatan Kesejahteraan Masyarakat dan Industri Kreatif yang Berdaya Saing. In Society, 1(1): 1-6.

Köse, T. E., \& Çalişkan Biroğul, N. (2016). Real textile wastewater reclamation using a combined coagulation/ flocculation/ membrane filtration system and the evaluation of several natural materials as flocculant aids. Gazi University Journal of Science, 29(3): 565-572.

Megawati. (2004). Kinetika reaksi oksidasi fero sulfat menjadi feri sulfat. [Tesis]. Universitas Gadjah Mada, Yogyakarta.
Olsen, E. D. (1986). Analytical chemistry, fourth edition (Christian, Gary D.). Journal of Chemical Education, 63(11).

Pass, G., Sutcliffe, H., Pass, G., \& Sutcliffe, H. (1974). Analytical Chemistry. Practical Inorganic Chemistry. Springer, Netherlands (pp. 39-48).

Risdianto, D. (2007). Optimisasi Proses Koagulasi Flokulasi untuk Pengolahan Air Limbah Industri Jamu (Studi Kasus PT. Sido Muncul). [Thesis]. Universitas Diponegoro, Semarang.

Rönnholm, M. R., Wärnå, J., Salmi, T., Turunen, I., \& Luoma, M. (1999). Kinetics of oxidation of ferrous sulfate with molecular oxygen. Chemical Engineering Science, 54(19): 4223-4232.

Undang-Undang Republik Indonesia Nomor 82 Tahun 2001. (2001). Undang-Undang Republik Indonesia Nomor 82 Tahun 2001, RI, Jakarta.

Vogel, A. I. (1985). Buku Teks Analisis Anorganik Kualitatif Makro dan Semimikro. In Edisi Ke-5, Kalman Media Pusaka, Jakarta.

Walker, R. (1993). Principles and prevention of corrosion. Materials \& Design, 14(3): 207.

Zahrim, A. Y., Tizaoui, C., \& Hilal, N. (2011). Coagulation with polymers for nanofiltration pre-treatment of highly concentrated dyes: A review. Desalination, 266(1-3): 1-16. 